\title{
Inversion Method of Initial In Situ Stress Field Based on BP Neural Network and Applying Loads to Unit Body
}

\author{
Xiaopeng Li, ${ }^{1}$ Xuejun $\mathrm{Zhou}^{2}{ }^{2}$ Zhengxuan $\mathrm{Xu},{ }^{2}$ Tao Feng, ${ }^{2}$ Dong Wang, ${ }^{1,2}$ Jianhui Deng, \\ Guangze Zhang, ${ }^{2}$ Cunbao Li, ${ }^{3}$ Gan Feng, ${ }^{1}$ Ru Zhang, ${ }^{1}$ Zhilong Zhang $\mathbb{D}^{1}{ }^{1}$ \\ and Zetian Zhang $\mathbb{D}^{1}$ \\ ${ }^{1}$ State Key Laboratory of Hydraulics and Mountain River Engineering, MOE Key Laboratory of Deep Earth Science and \\ Engineering, College of Water Resource and Hydropower, Sichuan University, Chengdu 610065, China \\ ${ }^{2}$ China Railway Eryuan Engineering Group Company, Ltd., Chengdu 610031, China \\ ${ }^{3}$ Guangdong Provincial Key Laboratory of Deep Earth Sciences and Geothermal Energy Exploitation and Utilization, \\ College of Civil and Transportation Engineering, Shenzhen University, Shenzhen 518060, China
}

Correspondence should be addressed to Zhilong Zhang; zzlxww@scu.edu.cn and Zetian Zhang; zhangzetian@scu.edu.cn

Received 11 September 2020; Revised 1 October 2020; Accepted 16 October 2020; Published 20 November 2020

Academic Editor: Chun Zhu

Copyright (C) 2020 Xiaopeng Li et al. This is an open access article distributed under the Creative Commons Attribution License, which permits unrestricted use, distribution, and reproduction in any medium, provided the original work is properly cited.

\begin{abstract}
The initial in situ stress field is the fundamental factor causing the deformation and failure of underground engineering and is an important basis for the feasibility analysis, design, and construction of underground engineering. However, it is difficult to obtain the whole in situ stress field of large-scale underground engineering in difficult and dangerous areas by field measurement. In view of the fact that the measured in situ stress components $\left(\sigma_{x x}, \sigma_{y y}, \sigma_{z z}, \tau_{x y}, \tau_{x z}, \tau_{y z}\right)$ of Sichuan-Tibet Railway in China are linear with the buried depth, a method is proposed to solve the in situ stress by applying corresponding loads to all unit bodies in the calculation area based on BP neural network and FLAC ${ }^{3 \mathrm{D}}$. Through this method, the in situ stress of the tunnel is inverted. The results show that both the maximum principal stress and minimum principal stress increase with the increase of buried depth, and when the tunnel passes through faults or anticlines, the main stress will suddenly drop. Furthermore, compared with the results of the multiple linear regression method, it is found that the proposed method has higher accuracy; especially for the simulation of the maximum horizontal principal stress and vertical stress, the average relative error is reduced by $26.44 \%$ and $77.27 \%$, respectively. The research in this paper can provide a new idea for the initial in situ stress inversion of engineering.
\end{abstract}

\section{Introduction}

The Sichuan-Tibet line in China extends from Chengdu to Lasa and is an important part of the integrated transportation system in Sichuan and Tibet [1]. The Sichuan-Tibet Railway is located in the mountainous area of southwest China with extremely complex geological conditions, facing the environment of high in situ stress, high temperature, and high permeability water. In situ stress and temperature, waterbody, disturbance, etc. are all important factors that affect the mechanical properties of rocks. Scholars have conducted research on rock mechanical properties in various environments [2-13]. They have carried out a lot of research on the physical model [5, 14-18], fractal [19-21], acoustic emission [22], energy evolution [23], etc., and they achieved some beneficial results. However, the most prominent surrounding rock environment of the SichuanTibet Railway in China is the high in situ stress. In situ stress affects the bearing capacity and stress propagation of rock mass, which is not only the fundamental force causing deformation and failure of underground engineering but also the necessary precondition for determining the mechanical response of tunnel surrounding rock, analyzing the stability of surrounding rock, and realizing the scientific design and decision-making of tunnel excavation [24, 25]. Therefore, in the process of design and construction of engineering, it is very important to grasp the distribution law of the initial in situ stress field.

Field measurements of in situ stress are the most direct methods to provide regional in situ stress field; the 
commonly used methods include overcoring, strain-relief, inverse solving methods, hydraulic fracturing test, borehole breakouts, acoustic emission, fault plane solution, differential strain analysis, and observation of discontinuity states [26-28]. However, due to the influence of factors such as site, funding, and testing technology, especially in the difficult and dangerous areas of southwest China, not only is the geological structure complicated, but also the terrain conditions on the ground are difficult, making it hard to conduct numerous and comprehensive measurements [29-31]. In addition, the measured in situ stress data reflects the characteristics of the local stress field to a large extent $[32,33]$. And there are many factors influencing the stress field of the rock mass. The measured results are affected by measurement errors, making the measured value usually show a large range. It is difficult to reflect the macroscopic law of the in situ stress field in the entire engineering area $[34,35]$. Therefore, in order to better meet the needs of engineering design and construction, it is necessary to combine the field engineering geological survey data and use effective calculation and analysis methods to invert the initial stress field and then infer the reasonable initial stress field in the project area [36-38].

At present, domestic and foreign scholars mainly use the following methods to simulate the initial stress field.

(1) Displacement back analysis method [39, 40]: In this method, an initial stress field is assumed, the mechanical parameters of rock mass are given, and the disturbed displacement field of excavation is obtained by numerical calculation. Then, the calculated displacement is compared with the in situ monitoring displacement. After adjusting the mechanical parameters of rock mass, the initial in situ stress field in line with the measured displacement is finally obtained. This method is suitable for the construction stage and cannot meet the needs of the engineering feasibility study and design stage. In addition, due to the restriction of geological conditions and measured data, the accuracy of the displacement back analysis method is difficult to guarantee.

(2) Boundary load adjustment method [41]: This method continuously adjusts the boundary load according to the set calculation domain, so that the calculated value of the stress field at a given measuring point under a certain working condition approaches the actual measured value. With a certain accuracy, the stress field obtained under this working condition can be used as the initial stress field. However, there is no rule to follow for the adjustment of boundary load, there is no theoretical basis for the uniqueness of the solution, and it is difficult to judge the convergence of the solution. Therefore, it is seldom used in regional initial stress field analysis.

(3) Stress function method [42, 43]: The basic idea of this method is to set a certain form of stress function to satisfy the harmonic equation based on the elastic theory and the distribution of the in situ stress field, which in turn satisfies the balance equation and deformation coordination conditions. Then, the stress function is used to obtain the in situ stress field of the calculation domain so that the calculated values on the given observation points are consistent with the measured values. This method is simple and easy to implement, and the calculation workload is small, but it is only suitable for conditions where the lithology is uniform and the regional geological structure is not too complicated.

(4) Displacement function method [44, 45]: This method assumes a certain form of displacement function based on the theory of elasticity, calculates the stress value of each measuring point, performs regression analysis with the measured stress value, and solves the regression coefficient. Then, based on this function, the displacement of each point on the boundary is estimated and applied to the model for the calculation to obtain the regional in situ stress field. Since the continuity of displacement is better than the continuity of stress in geotechnical engineering, the inversion of in situ stress by the displacement function method is superior to the stress function method. However, how to apply accurate displacement to each point on the boundary is difficult to achieve.

(5) Multiple linear regression analysis method [46-48]. The basic idea of this method is to establish a generalized geological model based on the topography and geomorphic characteristics and the distribution of rock layers, considering the stress field under gravity and tectonic action, and construct a multiple linear regression function, so that the inverted in situ stress field at the measuring point basically agrees with the measured value. This method has the advantages of convenience, quickness, ease of grasping, and uniqueness of the solution, so it is widely used in the engineering field [49]. However, this method is based on the superposition principle of elastic mechanics, which needs to satisfy elastic assumptions. Under complex geological conditions, the calculated in situ stress and the measured in situ stress after directly superimposing the boundary conditions according to the regression coefficient are often different.

(6) Nonlinear analysis methods based on artificial intelligence: With the rapid development of computer technology, nonlinear analysis methods such as gray theories [50], neural networks [51-53], and genetic algorithms [28] are widely used in the initial in-stress field inversion. This method uses the "black box" to establish the nonlinear relationship between load and stress and then solves the initial in situ stress. Since there is no need to make too many 
assumptions about the distribution of rock mass and stress field, it has the advantages of simple operation and strong applicability, but in order to meet the requirements of accuracy, a large number of samples are often needed.

It can be seen that there are many inversion methods for the initial in situ stress field, and each has advantages and disadvantages and applicable conditions. Based on the tunnel surrounding rock engineering of the Sichuan-Tibet Railway in China, this paper analyzes the types and distribution of the in situ stress field along the tunnel by the results of the in situ stress test. Aiming at the situation that each component of the measured in situ stress $\left(\sigma_{x x}, \sigma_{y y}, \sigma_{z z}\right.$, $\left.\tau_{x y}, \tau_{x z}, \tau_{y z}\right)$ is linear with the buried depth, by employing the BP neural network and FLAC ${ }^{3 \mathrm{D}}$ finite difference software, a method is proposed to solve the in situ stress field by applying corresponding loads to all unit bodies in the calculation area. Using this method, the in situ stress field of the surrounding rock of the tunnel is inverted and compared with the in situ stress field obtained by the most frequently used multiple linear regression method.

\section{Project Overview and Measured In Situ Stress Analysis}

2.1. Project Overview. A tunnel of the Sichuan-Tibet Railway has a total length of $18.81 \mathrm{~km}$ and a maximum buried depth of $1120 \mathrm{~m}$. It is an "extralong and extradeep" tunnel (Figure 1).

The tunnel traverses the Gaoersi Mountain Range, and the line runs in the east-west direction. The tunnel site is covered with a thick Quaternary soil layer. The ground is mostly covered by vegetation such as miscellaneous woods and cedar trees, and local rocks are exposed. The tunnel is relatively flat. Low-lying areas such as trenches are reclaimed as dry land or economic forests.

2.2. Measured In Situ Stress Analysis. The in situ stress test of the tunnel project in Sichuan-Tibet Railway adopted the hydraulic fracturing method, and the in situ stress test of two boreholes was carried out. The specific layout is shown in Figure 2.

Among them, ZK1 is located at DK402+601.68 m, the orifice elevation is $4359.40 \mathrm{~m}$, and the hole depth is $860.10 \mathrm{~m}$; ZK2 is located at DK411 $+514.92 \mathrm{~m}$, the orifice elevation is $4370.43 \mathrm{~m}$, and the hole depth is $1124.50 \mathrm{~m}$. In this hydraulic fracturing stress test, 10 sections of two boreholes were successfully measured. The measured data are shown in Table 1.

2.2.1. Measured In Situ Stress of Borehole ZK1. The measured in situ stress of ZK1 varies with the depth as shown in Figure 3, and the dominant direction of the maximum horizontal principal stress is the northwest direction.

The horizontal principal stress and vertical stress increase with the increase of depth. Within the test depth range, the vertical stress is $13.52 \mathrm{MPa} 20.93 \mathrm{MPa}$, and the maximum horizontal principal stress is
20.61 MPa 37.28 MPa. The minimum horizontal principal stress is $14.30 \mathrm{MPa} 22.56 \mathrm{MPa}$. The lateral pressure coefficient $K$ is the ratio of horizontal stress to vertical stress, and its value is $1.524 \sim 1.940$, indicating that the in situ stress field of the rock mass near the borehole is dominated by horizontal stress, and the type of in situ stress field in the surrounding rock near the borehole is $\sigma_{H}>\sigma_{h}>\sigma_{V}$. The relationship between the maximum and minimum horizontal principal stress and the depth is linearly fitted. The correlation coefficients are 0.9368 and 0.9879 , respectively, indicating that the horizontal principal stress has a good linear relationship with the depth.

2.2.2. Measured In Situ Stress of Borehole ZK2. The change law of ZK2 measured in situ stress with depth is shown in Figure 4 . The dominant direction of the maximum horizontal principal stress is the northwest direction.

Within the test depth range, the maximum horizontal principal stress is $18.69 \mathrm{MPa} 37.68 \mathrm{MPa}$, the minimum horizontal principal stress is $11.28 \mathrm{MPa} 21.09 \mathrm{MPa}$, and the vertical stress is $19.86 \mathrm{MPa} 26.57 \mathrm{MPa}$. The horizontal stress and vertical stress increase with the increase of depth. The lateral pressure coefficient $K$ is $0.941 \sim 1.418$, which indicates that the in situ stress field of the surrounding rock near the borehole is dominated by horizontal stress, and the type of the in situ stress field near the borehole is $\sigma_{H}>\sigma_{V}>\sigma_{h}$. The relationship between the maximum and minimum horizontal principal stress and the depth is linearly fitted. The correlation coefficients are 0.8652 and 0.8598 , respectively, indicating that the horizontal principal stress has a good linear fit with the depth.

\section{Inversion Method of the Initial In Situ Stress Based on BP Neural Network and Applying Loads to Unit Body}

3.1. Basic Principles. This method is suitable for the case that the stress components increase linearly with the buried depth. Since the stress at the ground surface is 0 , when the above conditions are met, the stress components of each unit body can be expressed as follows:

$$
\left\{\begin{array}{l}
\sigma_{x x_{i j k}}=k_{1} H_{i j k}, \\
\sigma_{y y_{i j k}}=k_{2} H_{i j k}, \\
\sigma_{z z_{i j k}}=k_{3} H_{i j k}, \\
\tau_{x y_{i j k}}=k_{4} H_{i j k}, \\
\tau_{x z_{i j k}}=k_{5} H_{i j k}, \\
\tau_{y z_{i j k}}=k_{6} H_{i j k},
\end{array}\right.
$$

where $i, j$, and $k$ are the numbers of units in the $X, Y$, and $Z$ directions, respectively. $\sigma_{x x i j k}, \sigma_{y y i j k}, \sigma_{z z i j k}, \tau_{x y i j k}, \tau_{x z i j k}$, and $\tau_{y z i j k}$ are the unit body stress components with coordinates $(i, j, k) . k_{1}, k_{2}, k_{3}, k_{4}, k_{5}$, and $k_{6}$ are the slopes where $\sigma_{x x}, \sigma_{y y}$, $\sigma_{z z}, \tau_{x y}, \tau_{x z}$, and $\tau_{y z}$ are linearly related to the buried depth. $H_{i j k}$ is the buried depth corresponding to the unit body with coordinates $(i, j, k)$. 


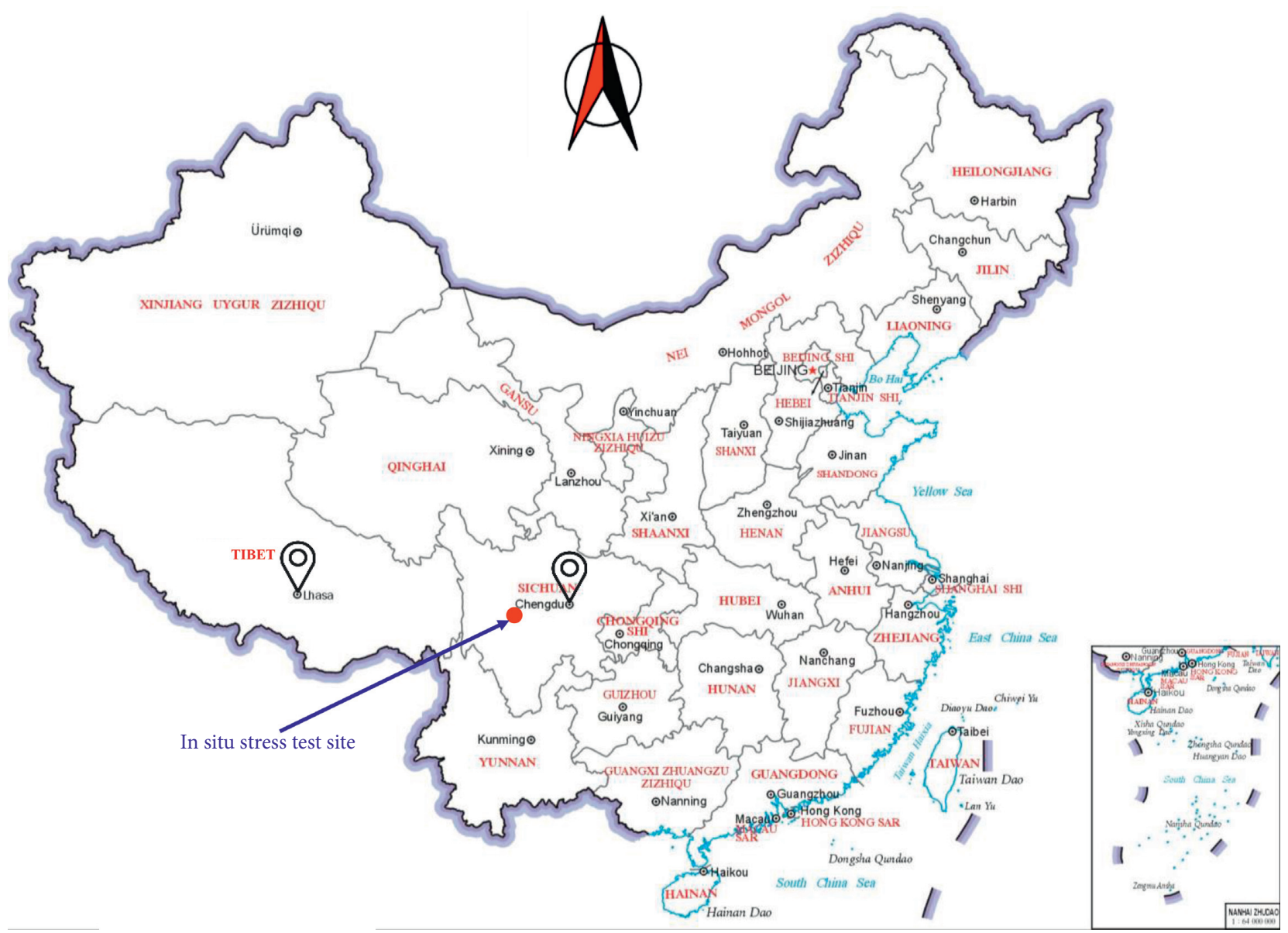

FIgURE 1: Geological location map of in situ stress test site.

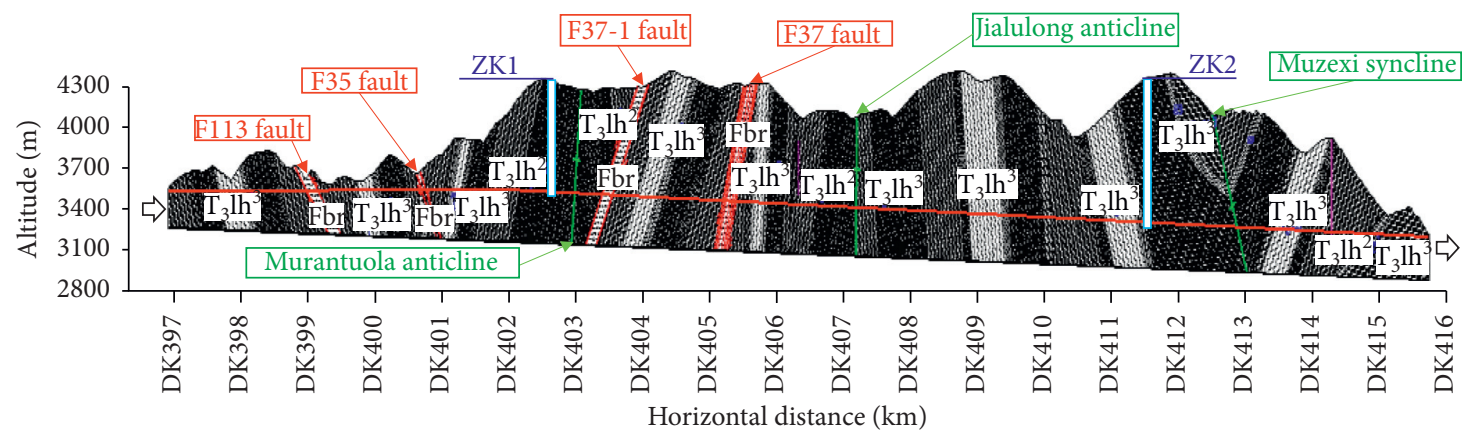

Figure 2: Borehole layout of the tunnel in Sichuan-Tibet Railway.

In order to obtain the stress components of all unit bodies, $k_{1}, k_{2}, k_{3}, k_{4}, k_{5}$, and $k_{6}$ need to be determined. Since traditional theories and methods are difficult to describe it accurately, BP neural network is introduced to carry out inversion analysis of $k_{1}, k_{2}, k_{3}, k_{4}, k_{5}$, and $k_{6}$. Finally, all the boundary conditions of the unit bodies satisfying the requirement of precision are obtained and brought into Flac ${ }^{3 \mathrm{D}}$ for equilibrium calculation. Thus, the initial in situ stress field is solved.

3.2. Model Establishment and Parameter Selection. In the process of building a 3D numerical model, seven faults are considered in the geological structure (F113 fault, F35 fault, F37-1 fault, F37 fault, Tongdagou fault, F118 fault, and F38 fault) and three folds (Muranlatuo anticline, Jialulong anticline, and Muzexi syncline). The lithology considered includes slate, sandstone, and slate-sandstone interbedding. Thus, a 3D numerical model is established (Figure 5).

The origin of the model is $(715421.228,3328060.160$, $0.000)$. Due north is taken as the positive direction of $Y$. The length of the model in the $X, Y$, and $Z$ directions is $20495 \mathrm{~m}$, $5000 \mathrm{~m}$, and $4350 \mathrm{~m}$, respectively (the elevation at the bottom of the model is $0 \mathrm{~m}$ ). And the mixed grid type is used (most of the models are hexahedral mesh, and some of them 
TABLE 1: In situ stress measurement results of hydraulic fracturing method.

\begin{tabular}{|c|c|c|c|c|c|c|c|}
\hline \multirow{2}{*}{ Borehole } & \multirow{2}{*}{ Measure-point } & \multirow{2}{*}{ Depth (m) } & \multirow{2}{*}{ Altitude (m) } & \multicolumn{3}{|c|}{ Stress $(\mathrm{MPa})$} & \multirow{2}{*}{ Fracture direction $\left(^{\circ}\right)$} \\
\hline & & & & $\sigma_{H}$ & $\sigma_{h}$ & $\sigma_{v}$ & \\
\hline \multirow{4}{*}{ ZK1 } & $1 \#$ & 520 & 3832.31 & 20.61 & 14.3 & 13.52 & $\mathrm{~N} 25^{\circ} \mathrm{W}$ \\
\hline & $2 \#$ & 635 & 3717.31 & 26.14 & 17.35 & 16.51 & $\mathrm{~N} 29^{\circ} \mathrm{W}$ \\
\hline & $3 \#$ & 735 & 3617.31 & 37.08 & 21.28 & 19.11 & $\mathrm{~N} 35^{\circ} \mathrm{W}$ \\
\hline & $4 \#$ & 805 & 3547.31 & 37.28 & 22.56 & 20.93 & - \\
\hline \multirow{6}{*}{ ZK2 } & 5\# & 764 & 3601.36 & 18.69 & 11.28 & 19.86 & - \\
\hline & $6 \#$ & 830 & 3535.36 & 21.39 & 12.35 & 21.58 & - \\
\hline & 7\# & 882 & 3483.36 & 22.03 & 13.73 & 22.93 & $\mathrm{~N} 59^{\circ} \mathrm{W}$ \\
\hline & $8 \#$ & 945 & 3420.36 & 26.81 & 14.78 & 24.57 & $\mathrm{~N} 55^{\circ} \mathrm{W}$ \\
\hline & 9\# & 974 & 3391.36 & 35.95 & 19.87 & 25.32 & $\mathrm{~N} 51^{\circ} \mathrm{W}$ \\
\hline & $10 \#$ & 1022 & 3343.36 & 37.68 & 21.09 & 26.57 & $\mathrm{~N} 56^{\circ} \mathrm{W}$ \\
\hline
\end{tabular}

$\sigma_{H}$ is the maximum horizontal principal stress, $\sigma_{h}$ is the minimum horizontal principal stress, $\sigma_{v}$ is the vertical stress.

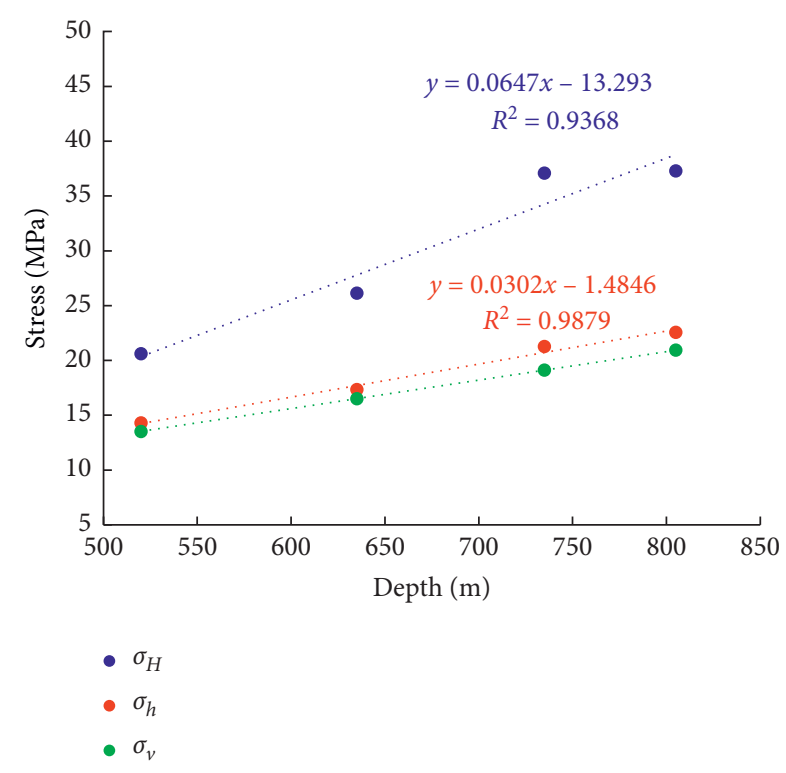

FIGURE 3: Variation of ZK1 measured in situ stress with depth.

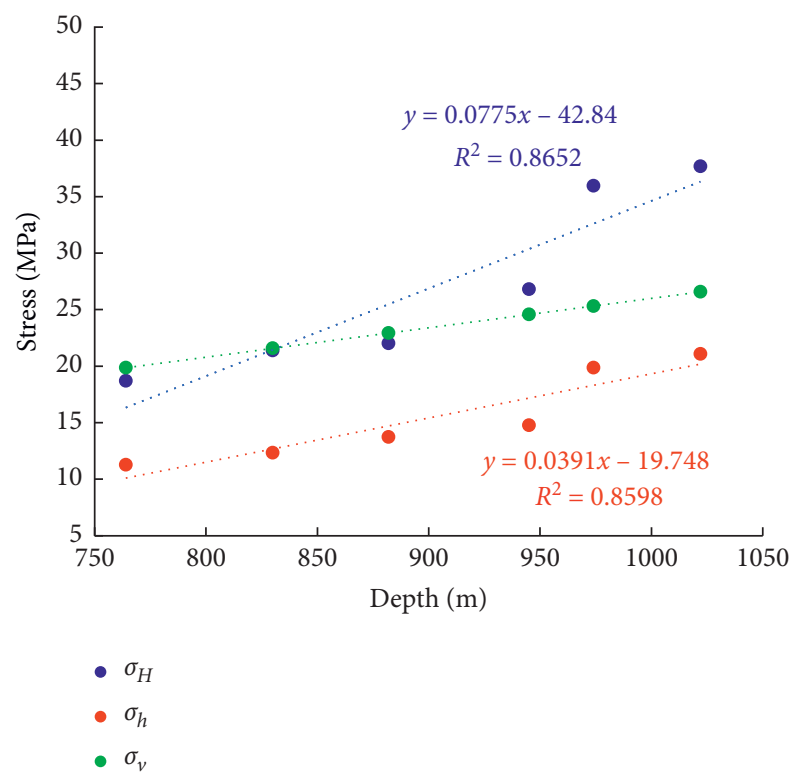

FIgURE 4: Variation of ZK2 measured in situ stress with depth. contain tetrahedral mesh), and a total of 2374068 nodes and 5346816 units are divided. According to the test results, the mechanical parameters of rock mass are obtained, as shown in Table 2.

3.3. Determination of Boundary Conditions. This method adopts the following two boundary conditions: (1) displacement boundary condition that constrains the model as a whole and (2) stress boundary condition that restricts the unit body.

3.3.1. Displacement Boundary Condition of Overall Model. A vertical displacement constraint is applied to the bottom in the $Z$ direction of the 3D numerical model along the tunnel line to constrain the displacement in the $Z$ direction of the model. The top of the model is a free surface without constraint. In addition, displacement constraints in $X$ and $Y$ directions are also applied at the ends of the $X$ and $Y$ directions, respectively, to constrain the horizontal displacement of the model, as shown in Figure 6.

3.3.2. Stress Boundary Conditions of Unit Bodies. The results of the in situ stress tests based on the hydraulic fracturing technique have no vertical plane shear stress $\tau_{x z}$ and $\tau_{y z}$, and the vertical stress $\sigma_{z z}$ is estimated by the thickness of the overlying strata and its bulk density. Therefore, in the numerical calculation, only $\sigma_{x x}, \sigma_{y y}$, and $\tau_{x y}$ should be considered. The added unit body load is shown in equation (2). As the measured in situ stress value is given in the geodetic coordinate system, it needs to be converted to the model coordinate system through equation (3). The relationship between the transformed stress components and the buried depth is shown in Figure 7. The stress components in borehole ZK1 and ZK2 showed a trend of increasing with the buried depth. Linear fitting is carried out for them, respectively, and the correlation coefficient is greater than 0.85 , satisfying the condition that the stress components of rock mass increase linearly with the buried depth. 


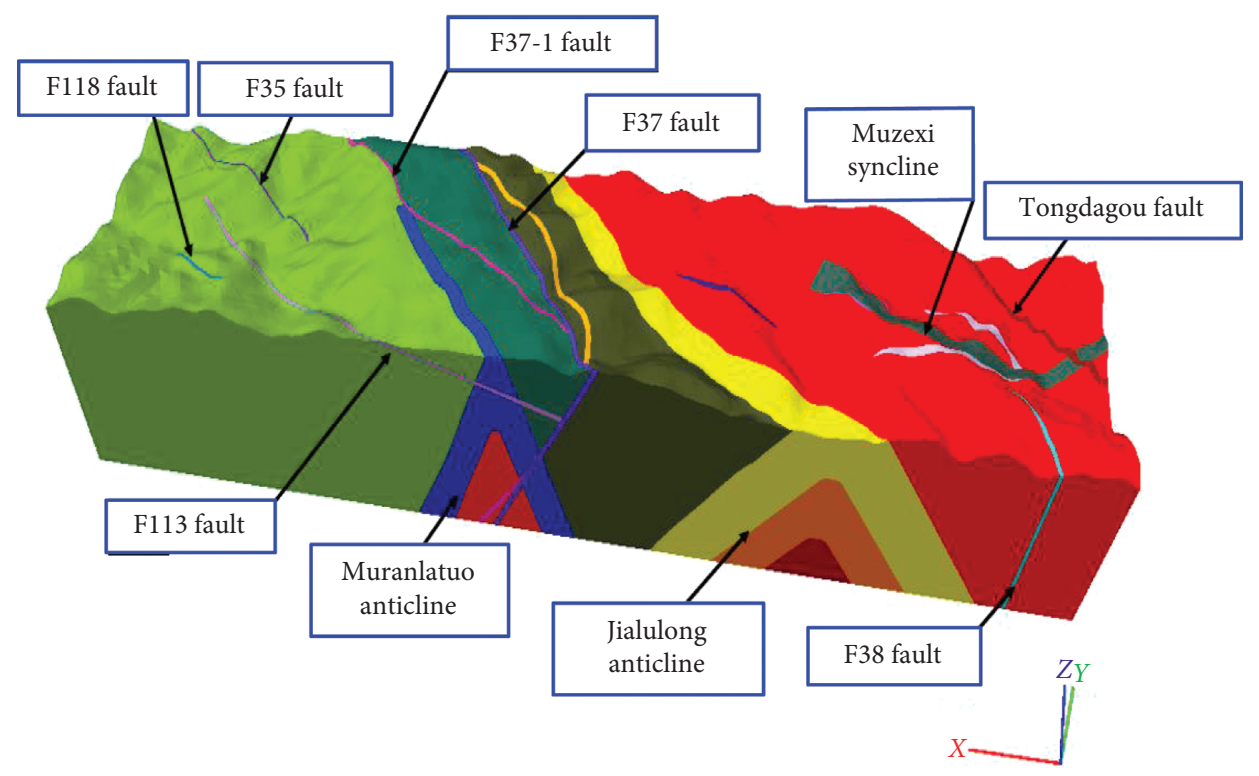

Figure 5: Three-dimensional numerical model of the tunnel in Sichuan-Tibet Railway.

TABLE 2: Mechanical parameters of rock mass.

\begin{tabular}{lcc}
\hline The type of rock & Deformation modulus (GPa) & Poisson's ratio \\
\hline Slate & 6 & 0.28 \\
Sandstone slate interbedding & 4.5 & 0.30 \\
Sandstone & 7 & 0.25 \\
Fault & 1.3 & 0.35 \\
Fold & 1.5 & 0.35 \\
\hline
\end{tabular}

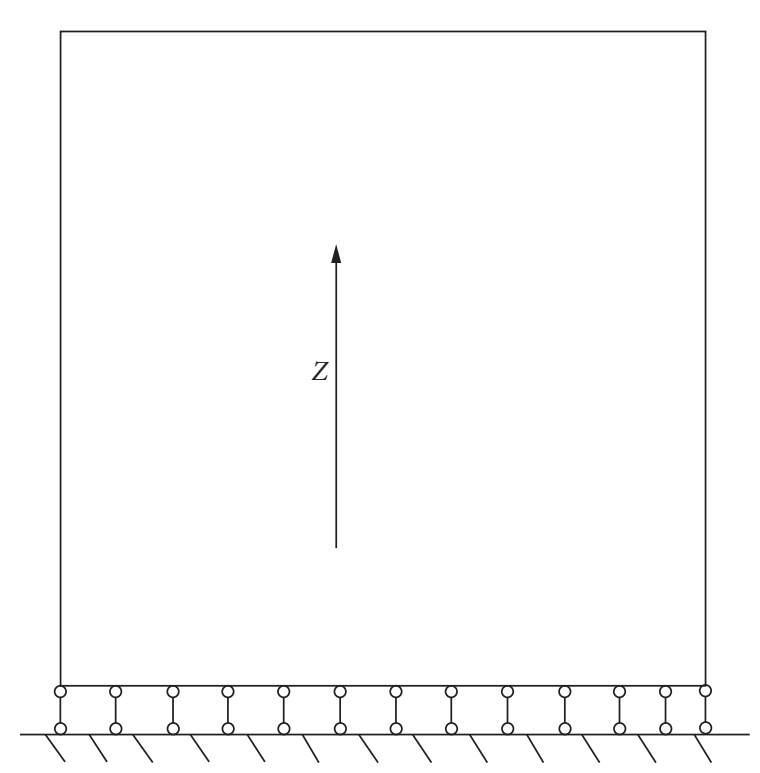

(a)

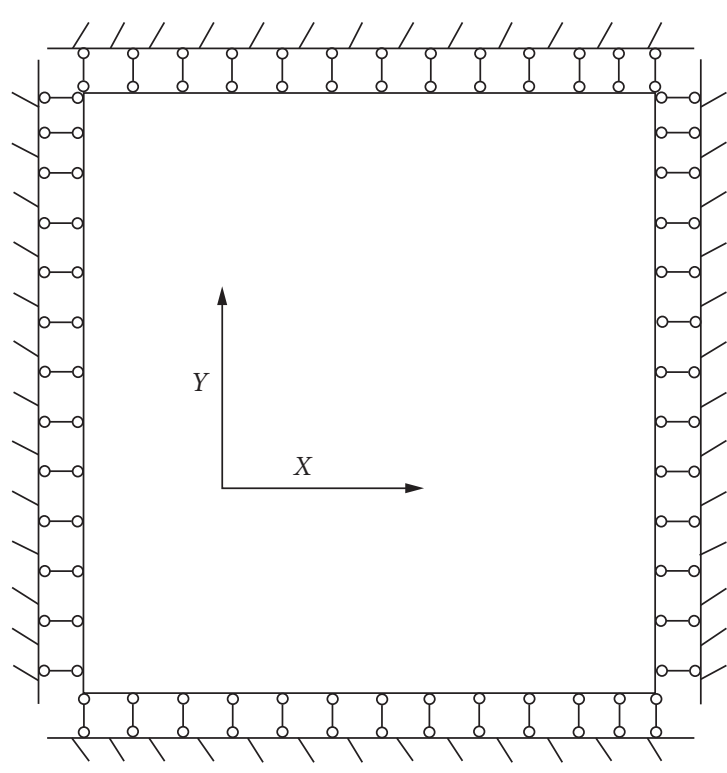

(b)

FiguRE 6: Displacement boundary conditions of global model. (a) Vertical displacement boundary conditions. (b) Horizontal displacement boundary conditions. 


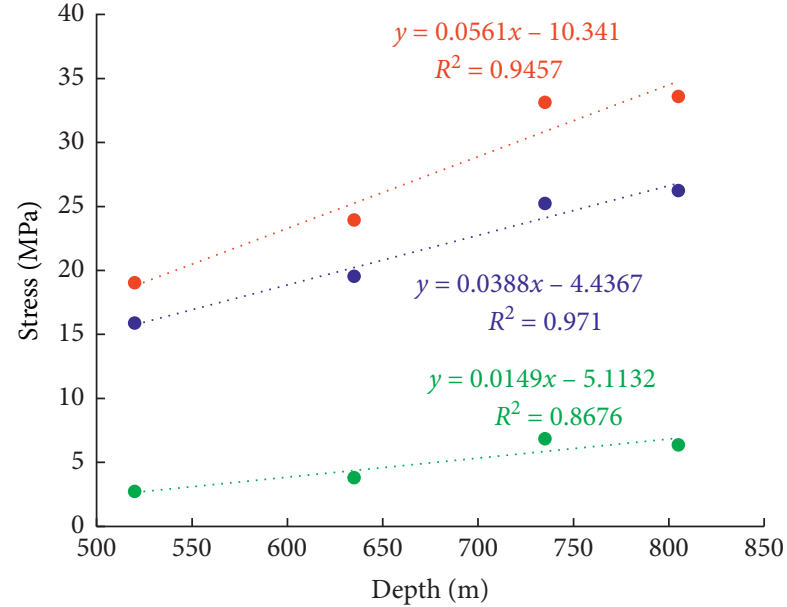

- $\sigma_{x x^{\prime}}$

- $\sigma_{y y^{\prime}}$

- $\tau_{x y^{\prime}}$

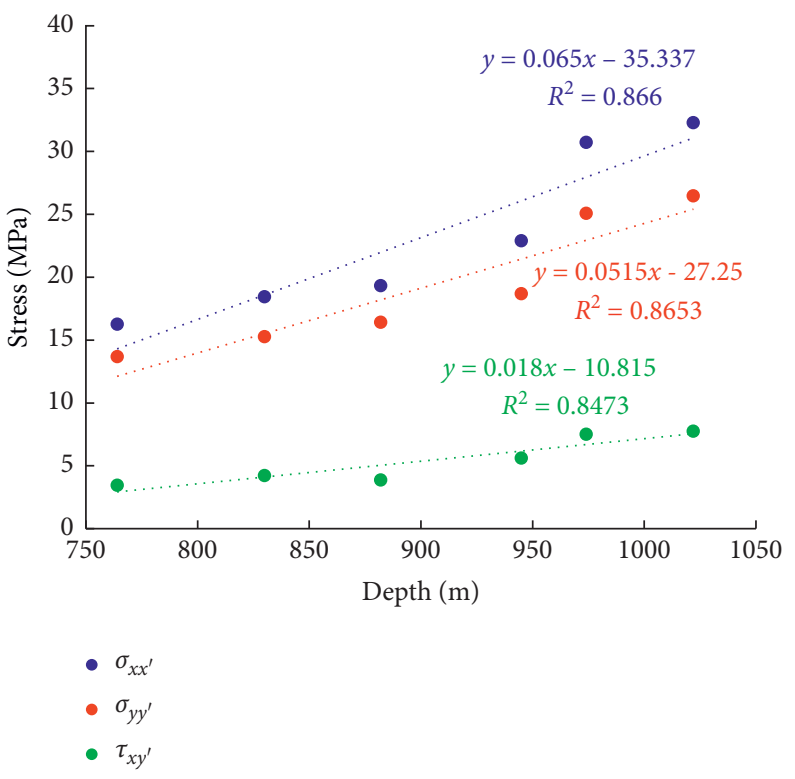

(b)

Figure 7: Variation of borehole stress components with buried depth in model coordinates. (a) ZK1. (b) ZK2.

$$
\begin{gathered}
\left\{\begin{array}{l}
\sigma_{x x_{i j k}}=k_{1} H_{i j k}, \\
\sigma_{y y_{i j k}}=k_{2} H_{i j k}, \\
\tau_{x y_{i j k}}=k_{4} H_{i j k},
\end{array}\right. \\
\left\{\begin{array}{l}
\sigma_{x x}^{\prime}=\sigma_{x x} l_{1}^{2}+\sigma_{y y} m_{1}^{2}+2 \tau_{x y} l_{1} m_{1}, \\
\sigma_{y y}^{\prime}=\sigma_{x x} l_{2}^{2}+\sigma_{y y} m_{2}^{2}+2 \tau_{x y} l_{2} m_{2}, \\
\tau_{x y}^{\prime}=\sigma_{x x} l_{1} l_{2}+\sigma_{y y} m_{1} m_{2}+2 \tau_{x y}\left(l_{1} m_{2}+l_{2} m_{1}\right),
\end{array}\right.
\end{gathered}
$$

where $l_{1}, l_{2}, m_{1}$, and $m_{2}$ are the direction cosines corresponding to the model coordinate system and the geodetic coordinate system, $\sigma_{x x}, \sigma_{y y}$, and $\tau_{x y}$ are the in situ stress, and $\sigma_{x x}^{\prime}, \sigma_{y y}^{\prime}$, and $\tau_{x y}^{\prime}$ are the stress in the model coordinate system.

BP neural network is the most widely used network model in the artificial neural network, with large-scale distributed processing capacity and high learning association ability. It can effectively solve extremely complex nonlinear problems in geotechnical engineering. Therefore, BP neural network is used to analyze $\sigma_{Z x x}, \sigma_{Z y y}$, and $\tau_{Z x y}$ in this paper. The basic steps are as follows.

According to the 3D numerical calculation model of the whole tunnel, the floating range of initial stress condition parameters of the model is determined on the basis of a large number of trial calculations. Then, five values within the floating range of each initial in situ stress condition parameter are selected. The 5 values of $k_{1}$ are $0.032,0.042$, $0.052,0.062$, and 0.072 , respectively. The 5 values of $k_{2}$ are $0.034,0.044,0.054,0.064$, and 0.074 , respectively. The 5 values of $k_{4}$ are $0,0.016,0.026,0.036$, and 0.046 , respectively. In order to save the time of calculation, the orthogonal experiment method is used to combine the values of different factors, and 25 combinations were generated in total.
The first 22 groups of samples were selected as training combinations, and the remaining 3 groups were test combinations. Then, based on Flac ${ }^{3 \mathrm{D}}$, the elastic model was used for the positive analysis and calculation of the above 25 combinations, and the input and output samples were obtained by taking the major and minor principal stress value of the calculated 10 measuring points as the input layer of the network, and the corresponding 3 stress boundary conditions as the output layer of the network.

BP neural network is trained with the training sample set. After 21894 times of training, the error reached the requirement of $\varepsilon=0.01$. The measured in situ stress values were input into the trained network, and the final stress boundary inversion results are shown in Table 3.

3.4. Comparison of Measured In Situ Stress in Borehole with Inversion Results. The parameter values in Table 3 are substituted into equation (2) and applied to the corresponding unit body in the $3 \mathrm{D}$ numerical model for calculation. The calculated in situ stress extracted from borehole $\mathrm{ZK} 1$ and $\mathrm{ZK} 2$ is compared with the measured results, as shown in Table 4.

It can be seen from Table 4 that the horizontal principal stress fitting errors of borehole $\mathrm{ZK} 1$ and $\mathrm{ZK} 2$ are relatively small in the deep, but slightly larger in the shallow. The maximum relative error is $29.40 \%$, less than $30 \%$, and the relative error of vertical stress at each measuring point is less than $10 \%$. According to the statistical data, the error of the initial in situ stress measurement results can reach $25 \%-30 \%$ [54]. Therefore, the inverse calculation of the initial in situ stress field by using this method can meet the requirements of engineering precision. 
TABLE 3: Inversion of stress boundary parameters.

\begin{tabular}{ll}
\hline Parameters & Value \\
\hline$k_{1}$ & 0.062 \\
$k_{2}$ & 0.058 \\
$k_{4}$ & 0.020 \\
\hline
\end{tabular}

3.5. Analysis of In Situ Stress on Tunnel Axis. The principle stress cloud map of the tunnel axis section is extracted, as shown in Figure 8. The "-" before the stress value represents the compressive stress, and the "+" represents the tensile stress. The maximum principal stress and minimum principal stress in the axial section of the tunnel generally increase with the increase of buried depth, and the minimum principal stress suddenly decreases in the vicinity of faults, synclines, and anticlines.

In order to grasp the distribution law of the axial stress field of the tunnel, the in situ stress near the tunnel body is extracted, as shown in Figure 9.

The maximum principal stress value near the tunnel body is between $10 \mathrm{MPa}$ and $48 \mathrm{MPa}$. The variation trend of the maximum principal stress of the tunnel body is similar to that of the buried depth of the tunnel. That is, the maximum principal stress of surrounding rock increases with the increase of buried depth, but it will decrease sharply when the tunnel goes through the fault and anticline. Take the F113 fault, Jialulong anticline, and Muzexi syncline as examples: the F113 fault intersects the tunnel body at $\mathrm{DK} 399+020 \sim \mathrm{DK} 399+80 \mathrm{~m}$. The fault is about $20 \sim 40 \mathrm{~m}$ wide, mainly manifested as strong cleavage, mudding, strong lensing, and obvious fault characteristics. The depth of this tunnel section is deeper than that on both sides, but under the influence of fault, the maximum principal stress of surrounding rock is lower than that on both sides. The Jialulong anticline intersects with the tunnel body at $\mathrm{DK} 407+230 \sim \mathrm{DK} 407+330 \mathrm{~m}$. The outcropping layer in the core is sericite slate, silty slate, and metasandstone interbedding in $T_{3} l h^{2}$. The buried depth of this tunnel section is deeper than that at DK407+000 m, but the surrounding rock at the core of the Jialulong anticline is relatively broken, and the major principle stress of confining pressure is smaller than that at DK407+000 m. The Muzexi syncline intersects with the tunnel body at $\mathrm{DK} 413+060 \sim \mathrm{DK} 413+160 \mathrm{~m}$. The tunnel is buried at a depth of $865 \mathrm{~m}$. The outcropping layer in the core is sandy slate, sericite slate, carbonaceous sericite slate, and carbonaceous slate laminated phyllite intercalated with quartz sandstone. In addition, the surrounding rock of the syncline core is relatively broken, so the maximum principal stress of the tunnel is less than that of the surrounding rock on both sides.

The relationship between the maximum principal stress and the buried depth was plotted, as shown in Figure 10.

It can be found from Figure 10 that the relationship between the maximum principal stress of surrounding rock and the buried depth of this railway tunnel is linearly increased, as shown in the following equation. Through this equation, we can roughly calculate the maximum principal stress in this area according to the buried depth in the preliminary design, which has a certain value for the design and construction of underground engineering in the Sichuan-Tibet Railway.

$$
\sigma_{1}=0.0269 H+13.58
$$

where $\sigma_{1}$ is the maximum principal stress $(\mathrm{MPa})$ and $H$ is the buried depth $(\mathrm{m})$.

\section{Multiple Linear Regression Analysis and Inversion Results}

The steps of the multiple linear regression method are as follows.

(1) A 3D calculation model was established based on the known geological and topographic survey test data.

(2) The factors that may form the initial in situ stress field (gravity, tectonic movement, temperature, etc.) are taken as undetermined factors, and the stress at known points is obtained by numerical calculation for each undetermined factor. Then, a multiple regression equation is established between the stress calculated by each undetermined factor and the stress measured at known points.

(3) By statistical analysis method (the least-square method), the optimal solution of coefficients of variables (undetermined factors) in the multiple regression equation is obtained according to the principle of the minimum sum of squares of residual error. At the same time, in the solution process, the factors to be determined can be screened, with significant contributions introduced and insignificant elimination, so as to obtain the distribution law of the initial in situ stress field in the region.

Lots of engineering practices show that gravity and geological tectonism are the main factors for the formation of rock mass ground stress field. The effect of temperature and groundwater is relatively small and negligible and difficult to quantify $[55,56]$. In this paper, the gravity of rock mass and geological tectonism were selected as the basic influencing factors to be regressed. Due to the limitation of the principle of hydraulic fracturing method, four factors were determined as the basic factors to simulate the gravity of rock mass and geological tectonism: gravity, east-west horizontal extrusion tectonic movement, south-north horizontal extrusion tectonic movement, and uniform shear tectonic movement in the horizontal plane. Considering the uncertainty of the tectonic movement, the displacement method was used to simulate the tectonic movement [57]. Under the separate influence of the above basic factors, the corresponding load and boundary constraint conditions are shown in Figure 11.

Based on the above analysis, the regression in situ stress field can be expressed as 
TABLe 4: Comparison between measured and calculated in stress values of the tunnel in Sichuan-Tibet Railway.

\begin{tabular}{lcccccccc}
\hline \multirow{2}{*}{ Measure-point } & \multicolumn{3}{c}{ Measured in situ stress $(\mathrm{MPa})$} & \multicolumn{3}{c}{ Calculated in situ stress (MPa) } & \multicolumn{3}{c}{ Relative error (\%) } \\
& $\sigma_{H}$ & $\sigma_{h}$ & $\sigma_{v}$ & $\sigma_{H}$ & $\sigma_{h}$ & $\sigma_{v}$ & $\sigma_{H}$ & $\sigma_{h}$ \\
\hline 1\# & 20.61 & 14.3 & 13.52 & 26.67 & 13.18 & 14.7 & 29.40 & 7.83 \\
2\# & 26.14 & 17.35 & 16.51 & 28.82 & 15.85 & 16.38 & 10.25 & 8.65 \\
3\# & 37.08 & 21.28 & 19.11 & 32.3 & 20.62 & 19.33 & 12.89 & 3.10 \\
4\# & 37.28 & 22.56 & 20.93 & 33.34 & 22.17 & 20.22 & 10.57 & 1.73 \\
5\# & 18.69 & 11.28 & 19.86 & 20.37 & 13.58 & 20.75 & 8.99 & 20.39 \\
6\# & 21.39 & 12.35 & 21.58 & 23.24 & 15.93 & 21.43 & 8.65 & 28.99 \\
7\# & 22.03 & 13.73 & 22.93 & 24.77 & 16.41 & 22.89 & 12.44 & 19.52 \\
8\# & 26.81 & 14.78 & 24.57 & 28.74 & 19.13 & 25.01 & 7.20 & 29.43 \\
9\# & 35.95 & 19.87 & 25.32 & 31.97 & 21.24 & 26.66 & 11.07 & 6.89 \\
10\# & 37.68 & 21.09 & 26.57 & 33.55 & 22.29 & 27.97 & 10.96 & 5.79 \\
\hline
\end{tabular}

Relative error $=\mid$ calculated in situ stress - measured in situ stress $\mid /$ measured in situ stress $\times 100 \%$.

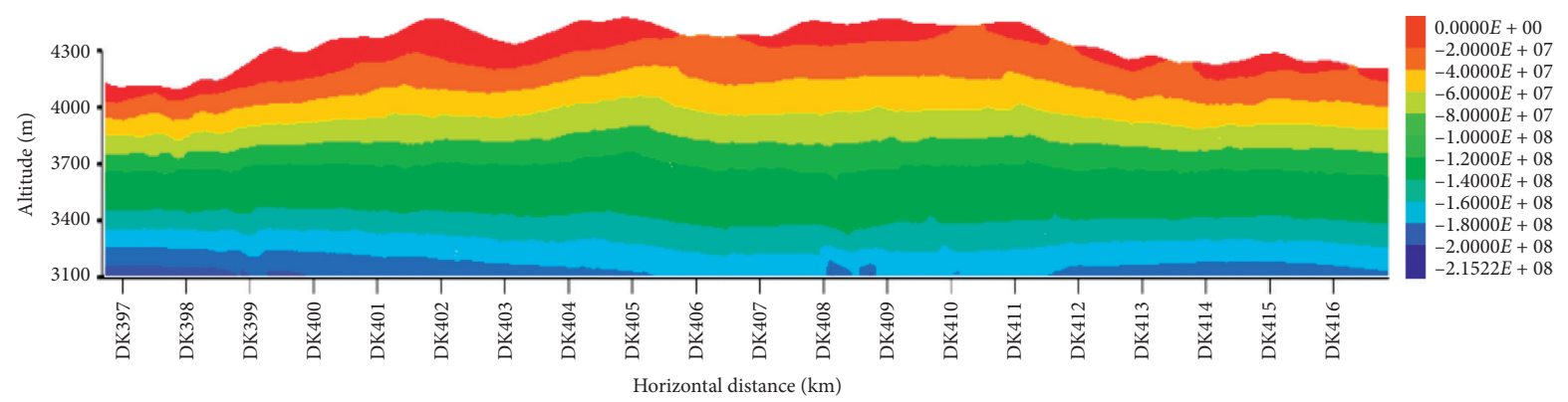

(a)

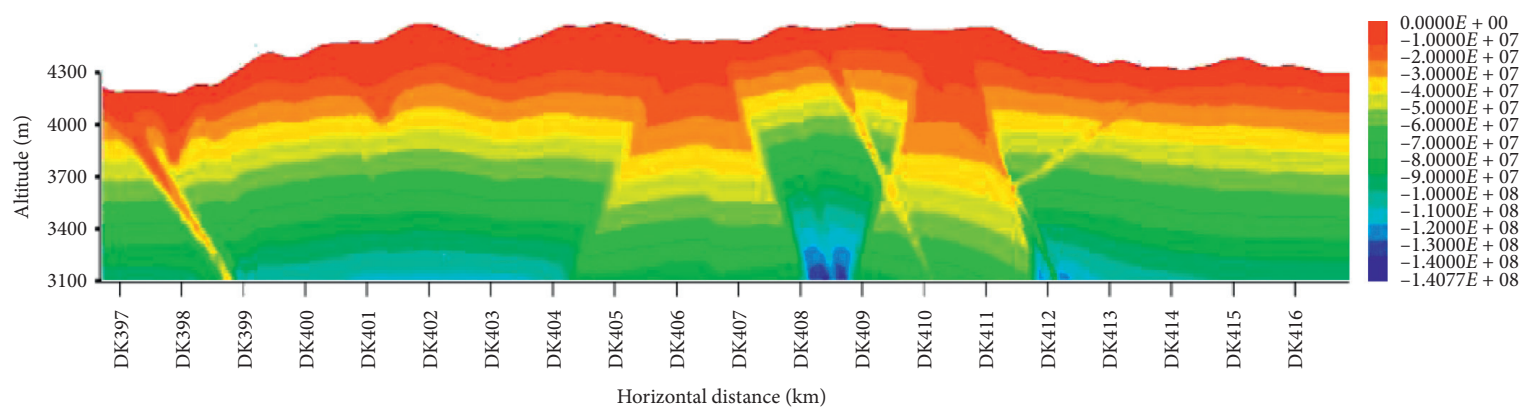

(b)

Figure 8: The principal stress nephogram of the tunnel axis section. (a) The maximum principal stress nephogram of the tunnel. (b) The minimum principal stress nephogram of the tunnel.

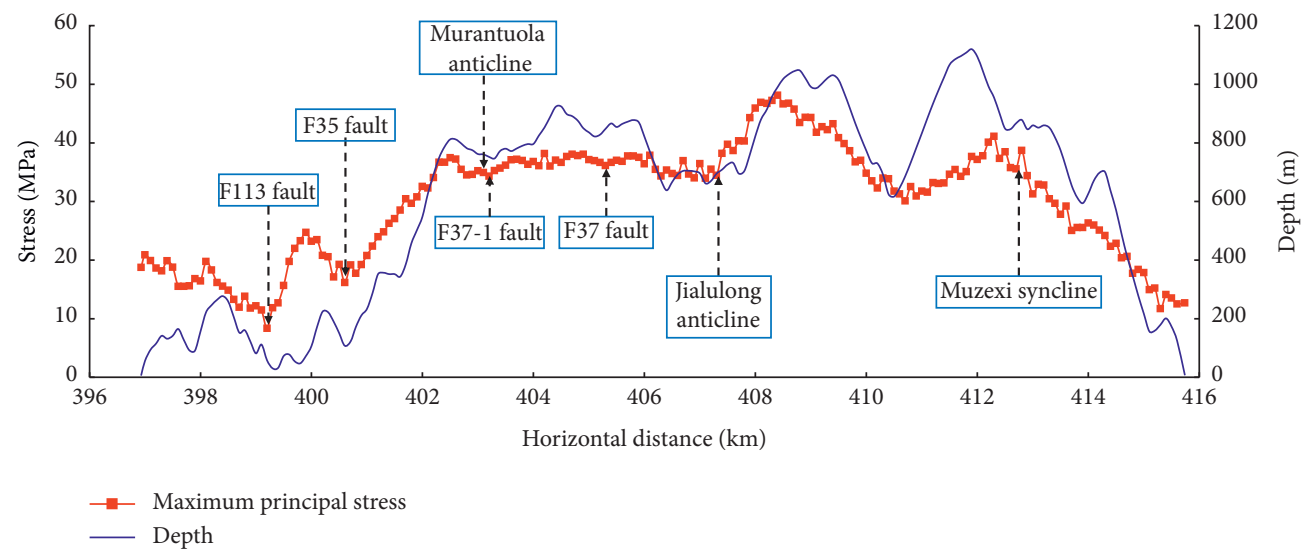

FIgURE 9: In situ stress variation of the tunnel axis. 


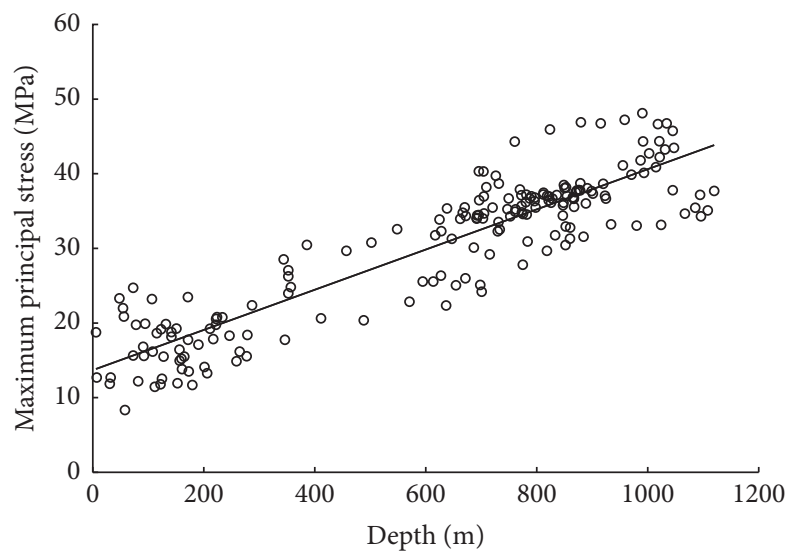

FIgURE 10: Relationship between the maximum principal stress and the buried depth.

$$
\sigma_{\mathrm{CS}}=L_{1} \sigma_{\mathrm{TS} 1}+L_{2} \sigma_{\mathrm{TS} 1 \Delta}+L_{3} \sigma_{\mathrm{TS} 2}+L_{4} \sigma_{\mathrm{TS} 2 \Delta}+L_{5} \sigma_{\mathrm{TS} 3}+L_{6} \sigma_{\mathrm{TS} 4}+L_{7} \sigma_{\mathrm{SWS}}+e_{k} \text {, }
$$

where $\sigma_{\mathrm{CS}}$ is the initial in situ stress, $\sigma_{\mathrm{TS} 1}$ is the 1-meter uniform compression displacement applied along the east-west horizontal direction, $\sigma_{\mathrm{TS} 2}$ is the 1-meter uniform compression displacement applied along the north-south horizontal direction, $\sigma_{\mathrm{TS} 1 \Delta}$ is the triangular distribution extrusion displacement with vertical depth change gradient of $1 \mathrm{~cm} / \mathrm{m}$ applied along the east-west horizontal direction, $\sigma_{\mathrm{TS} 2 \Delta}$ is the triangular distribution extrusion displacement with vertical depth change gradient of $1 \mathrm{~cm} / \mathrm{m}$ applied along the north-south horizontal direction, $\sigma_{\mathrm{TS} 3}$ is the uniformly distributed displacement along the east-west direction of $1 \mathrm{~m}$ in the horizontal plane, $\sigma_{\mathrm{TS} 4}$ is the uniformly distributed displacement along the north-south direction $1 \mathrm{~m}$ in the horizontal plane, $\sigma_{\mathrm{Sws}}$ is the gravity, $e_{k}$ is the random variable, and $L_{1} \sim L_{7}$ is the regression coefficient.

The three-dimensional numerical model and rock mechanical parameters were all based on the contents in Chapter 3. The elastic model of $\mathrm{Flac}^{3 \mathrm{D}}$ was used to simulate the above seven conditions, respectively, and the initial in situ stress field regression equation of the tunnel is obtained as follows:

$$
\sigma_{\mathrm{CS}}=14.7 \sigma_{\mathrm{TS} 1}+362.0 \sigma_{\mathrm{TS} 1 \Delta}+6.1 \sigma_{\mathrm{TS} 2}+275.8 \sigma_{\mathrm{TS} 2 \Delta}-14.1 \sigma_{\mathrm{TS} 3}-37.5 \sigma_{\mathrm{TS} 4}+1.0 \sigma_{\mathrm{SWS}}+1.1
$$

To test the relevance and rationality of equation (6), the following indexes shall be calculated:

$$
\begin{aligned}
& Q=\sum_{n=1}^{40}\left(\sigma_{n}-\widehat{\sigma}_{n}\right)^{2}, \\
& U=\sum_{n=1}^{40}\left(\widehat{\sigma}_{n}-\bar{\sigma}_{n}\right)^{2}, \\
& R=\sqrt{\frac{U}{Q+U}}, \\
& F=\frac{(U / m)}{(Q /(n-m-1))},
\end{aligned}
$$

where $Q$ is the regression residual sum of squares, $U$ is the regression sum of squares, $R$ is the multiple correlation coefficient, $F$ is the significance test observations in $F$ distribution, $\sigma_{n}$ is the measured in situ stress, $\bar{\sigma}_{n}$ is the mean values of measured in situ stress, $\widehat{\sigma}_{n}$ is the calculated value of in situ stress after linear regression, $n$ is the class number of measured in situ stress, and $m$ is the number of factors to be regressed.

By calculating equations (7)-(10), $Q=498.928$, $U=2441.360$, and $R=0.9112$ are obtained. The above results show that the correlation of the regression formula is good. $F$, the significance test observations, is equal to 77.968 , more than the critical value $F(7,40-7-1)=2.31$ at the significance level of 0.05 . Therefore, it can be considered that the overall effect of these 7 independent variables is significant.

Through the equilibrium calculation of the stress field, the regression stress value of each measuring point under the calculated coordinate system is obtained. The measured in situ stress value and the regression principal stress value of 


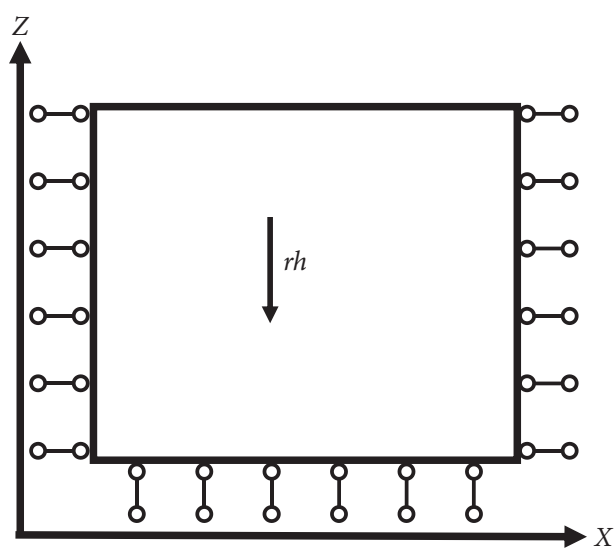

(a)

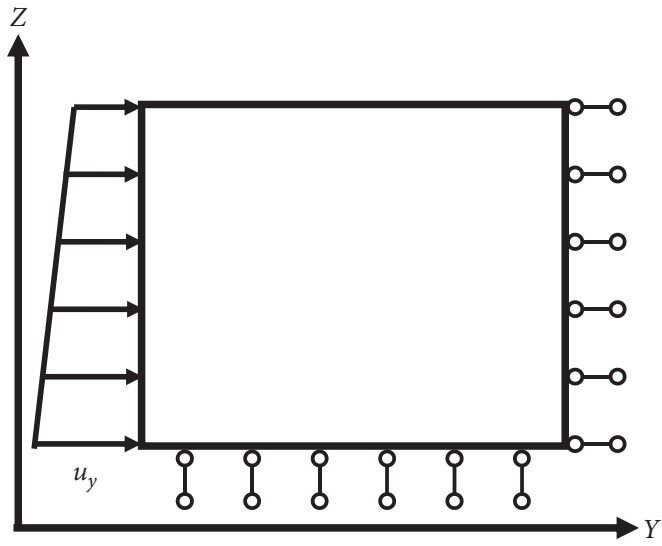

(c)

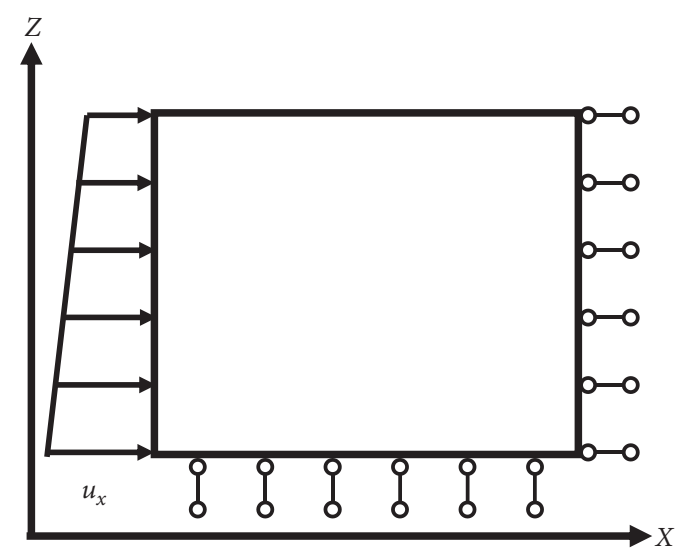

(b)

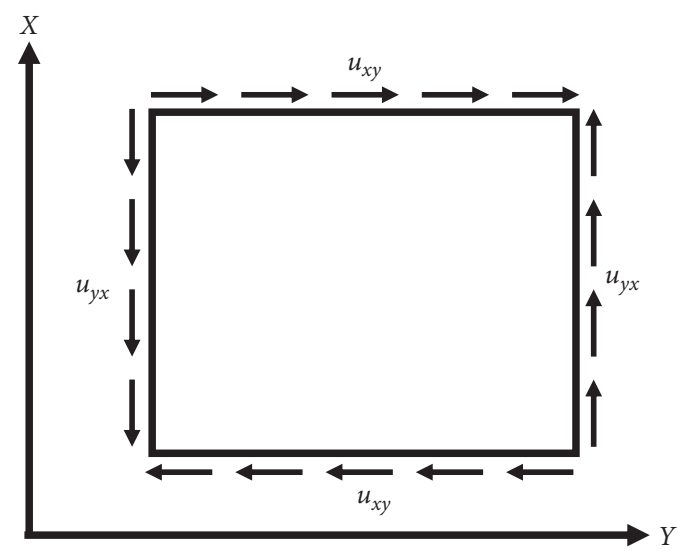

(d)

FIGURE 11: Schematic diagram of applied loads and boundary constraints. (a) Gravity. (b) East-West compression. (c) North-South compression. (d) Horizontal shear.

TABle 5: Comparison between measured and calculated in situ stress values of the tunnel in Sichuan-Tibet Railway.

\begin{tabular}{|c|c|c|c|c|c|c|c|c|c|}
\hline \multirow{2}{*}{ Measure-point } & \multicolumn{3}{|c|}{ Measured in situ stress (MPa) } & \multicolumn{3}{|c|}{ Calculated in situ stress $(\mathrm{MPa})$} & \multicolumn{3}{|c|}{ Relative error (\%) } \\
\hline & $\sigma_{H}$ & $\sigma_{h}$ & $\sigma_{v}$ & $\sigma_{H}$ & $\sigma_{h}$ & $\sigma_{v}$ & $\sigma_{H}$ & $\sigma_{h}$ & $\sigma_{v}$ \\
\hline $1 \#$ & 20.61 & 14.3 & 13.52 & 24.23 & 18.19 & 16.82 & 17.55 & 27.19 & 24.38 \\
\hline $2 \#$ & 26.14 & 17.35 & 16.51 & 26.44 & 18.44 & 18.85 & 1.15 & 6.26 & 14.18 \\
\hline $3 \#$ & 37.08 & 21.28 & 19.11 & 30.95 & 17.48 & 21.68 & 16.54 & 17.86 & 13.45 \\
\hline $4 \#$ & 37.28 & 22.56 & 20.93 & 30.86 & 17.48 & 23.51 & 17.21 & 22.53 & 12.34 \\
\hline $5 \#$ & 18.69 & 11.28 & 19.86 & 24.21 & 12.12 & 17.55 & 29.56 & 7.46 & 11.61 \\
\hline $6 \#$ & 21.39 & 12.35 & 21.58 & 23.74 & 14.17 & 17.64 & 11.00 & 14.77 & 18.27 \\
\hline $7 \#$ & 22.03 & 13.73 & 22.93 & 24.81 & 14.65 & 19.30 & 12.62 & 6.71 & 15.83 \\
\hline $8 \#$ & 26.81 & 14.78 & 24.57 & 25.64 & 16.68 & 21.53 & 4.37 & 12.86 & 12.36 \\
\hline 9\# & 35.95 & 19.87 & 25.32 & 25.84 & 17.80 & 22.87 & 28.13 & 10.42 & 9.69 \\
\hline $10 \#$ & 37.68 & 21.09 & 26.57 & 27.01 & 19.56 & 24.49 & 28.31 & 7.26 & 7.82 \\
\hline
\end{tabular}

Relative error $=\mid$ calculated in situ stress - measured in situ stress $\mid /$ measured in situ stress $\times 100 \%$.

TABLE 6: The average relative error of two methods.

\begin{tabular}{lccc}
\hline Method & $\varepsilon_{\sigma H}$ & $\varepsilon_{\sigma h}$ & \\
\hline This paper & $12.24 \%$ & $13.22 \%$ & $3.18 \%$ \\
Multiple linear regression & $16.64 \%$ & $13.33 \%$ & $13.99 \%$ \\
\hline
\end{tabular}

$\varepsilon_{\sigma H}$ is the average relative error of maximum horizontal principal stress, $\varepsilon_{\sigma h}$ is the average relative error of minimum horizontal principal stress, $\varepsilon_{\sigma v}$ is average relative error of vertical stress. 


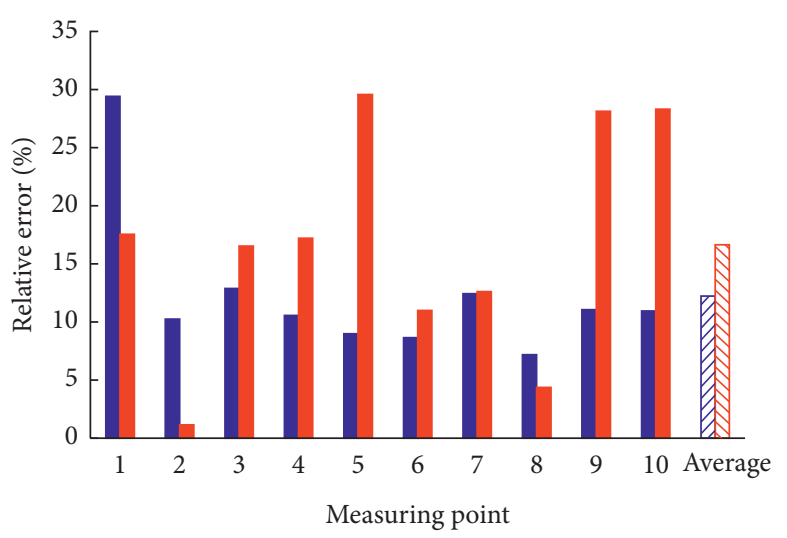

- This paper

- Multiple linear regression

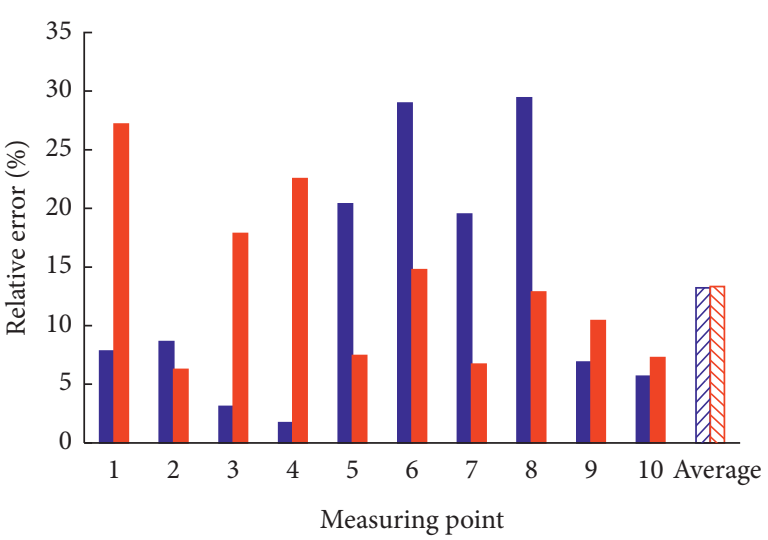

- This paper

- Multiple linear regression

(a)

(b)

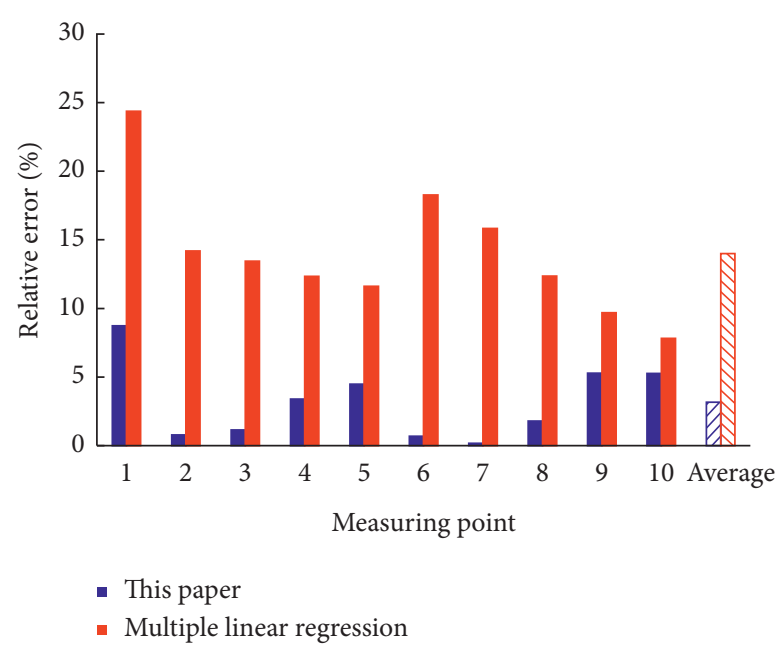

(c)

FIgURE 12: Comparative analysis of the relative error between two methods. (a) $\varepsilon_{\sigma H}$. (b) $\varepsilon_{\sigma h}$. (c) $\varepsilon_{\sigma v}$.

the measuring point are shown in Table 5. The maximum relative error of the stress fitting in the borehole ZK1 and ZK2 is $29.56 \%$, less than $30 \%$, which can meet the accuracy requirements of the engineering.

\section{Comparison and Analysis of the Inversion Results of the Two Methods}

In order to compare the inversion accuracy between the proposed method and the multiple linear regression method, the average relative error of the 10 measuring points is calculated, respectively, as shown in Table 6 and Figure 12 .

It can be seen from Figure 12 that the method in this paper has higher accuracy in the inversion analysis of maximum principal stress, minimum principal stress, and vertical stress. In particular, the average relative errors of maximum horizontal principal stress $\sigma_{H}$ and vertical stress $\sigma_{v}$ are reduced by $26.44 \%$ and $77.27 \%$, respectively.
In addition, in terms of calculating the whole field of initial in situ stress in the area, the multiple linear regression method needs to calculate the stress at each point in the model according to equation (6), so it is difficult to intuitively show the whole field of initial in situ stress. However, the method in this paper only needs to apply the stress boundary conditions obtained by inversion to the corresponding unit body, and then the initial in situ stress of the whole field can be calculated by Flac ${ }^{3 \mathrm{D}}$. Therefore, compared with the multiple linear regression method, the method in this paper has the advantages of convenience, quickness, and a higher degree of visualization.

\section{Conclusion}

Based on the in situ stress test results, the types and distribution laws of in situ stress field along the tunnel of the Sichuan-Tibet Railway were analyzed in this paper. It is 
found that the horizontal principal stress and vertical stress increase with the increasing buried depth and have a good linear relationship. Furthermore, the stress components in the model coordinate system were analyzed, and it is found that there is a good linear relationship between the measured in situ stress components and the buried depth. Based on this, combined with BP neural network and FLAC ${ }^{3 \mathrm{D}}$, a method is proposed to solve the in situ stress field by applying corresponding loads to all unit bodies in the calculation area. This method and the multiple linear regression method were used to invert the initial in situ stress of the tunnel, respectively, and the results were compared. The main conclusions obtained are as follows:

(1) Based on the initial in situ inversion method proposed in this paper by the BP neural network and applying loads to the unit body, the horizontal principal stress fitting error of borehole ZK1 and ZK2 is smaller in the deep part and slightly larger in the shallow part. The maximum relative error is $29.40 \%$, less than $30 \%$, and the relative error of the vertical stress of each measuring point is less than $10 \%$, which can meet the accuracy requirements of the engineering.

(2) The multiple linear regression method is applied to the inversion of the initial in situ stress field of the tunnel. The maximum relative error of the stress fitting in the borehole ZK1 and ZK2 is $29.56 \%$, less than $30 \%$.

(3) Comparing the proposed method with the multiple linear regression method, it is found that the proposed method has higher accuracy; especially for the simulation of $\sigma_{H}$ and $\sigma_{v}$, the average relative errors are reduced by $26.44 \%$ and $77.27 \%$, respectively. And this method can also directly obtain all the initial in situ stress field in the calculation area, so as to facilitate the subsequent excavation simulation of the whole tunnel.

In summary, the research in this paper can provide a new idea for the inversion of the initial in situ stress field, in order to better provide more accurate in situ stress conditions for the design, construction, and operation of the engineering.

\section{Data Availability}

The data used to support the findings of this study are included within the article.

\section{Conflicts of Interest}

The authors declare no conflicts of interest.

\section{Acknowledgments}

Financial supports from the Key R\&D Projects of Sichuan Science and Technology Plan under Grant no. 19YFG0047, and the research project of China Railway Eryuan Engineering Group Company, Ltd., under Grant no. 19H0537, and the China Postdoctoral Science Foundation under Grant No. 2019T120841 are gratefully acknowledged.

\section{References}

[1] G. S. Hu, C. Y. Zhao, N. S. Chen, K. T. Chen, and T. Wang, "Characteristics, mechanisms and prevention modes of debris flows in an arid seismically active region along the SichuanTibet railway route, China: a case study of the Basu-Ranwu section, southeastern Tibet," Environmental Earth Sciences, vol. 78, no. 18, pp. 1-18, 2019.

[2] G. Feng, Y. Kang, and X. C. Wang, "Fracture failure of granite after varied durations of thermal treatment: an experimental study," Royal Society Open Science, vol. 6, no. 1, pp. 1-12, 2019.

[3] M. R. M. Aliha, F. Berto, A. Mousavi, and S. M. J. Razavi, "On the applicability of ASED criterion for predicting mixed mode I + II fracture toughness results of a rock material," Theoretical and Applied Fracture Mechanics, vol. 92, pp. 198-204, 2017.

[4] T. Meng, J. Xie, X. M. Li, J. W. Ma, and Y. Yue, "Experimental study on the evolutional trend of pore structures and fractal dimension of low-rank clay rich coal subjected to a coupled thermo-hydro-mechanical-chemical environment," Energy, vol. 203, 2020.

[5] C. Zhu, M. C. He, M. Karakus, X. B. Cui, and Z. G. Tao, "Investigating toppling failure mechanism of anti-dip layered slope due to excavation by physical modelling," Rock Mechanics and Rock Engineering, 2020.

[6] H. Huang, T. Babadagli, X. Chen, H. Z. Li, and Y. M. Zhang, "Performance comparison of novel chemical agents for mitigating water-blocking problem in tight gas sandstones," SPE Reservoir Evaluation \& Engineering, 2020.

[7] G. Feng, X. Wang, M. Wang, and Y. Kang, "Experimental investigation of thermal cycling effect on fracture characteristics of granite in a geothermal-energy reservoir," Engineering Fracture Mechanics, vol. 235, Article ID 107180, 2020.

[8] B. L. A. Isaka, P. G. Ranjith, T. D. Rathnaweera, M. S. A. Perera, and W. G. P. Kumari, "Influence of long-term operation of supercritical carbon dioxide based enhanced geothermal system on mineralogical and microstructurallyinduced mechanical alteration of surrounding rock mass," Renewable Energy, vol. 136, pp. 428-441, 2019.

[9] G. Feng, Y. Kang, X. Wang, Y. Hu, and X. Li, "Investigation on the failure characteristics and fracture classification of shale under Brazilian test conditions," Rock Mechanics and Rock Engineering, vol. 53, no. 7, pp. 3325-3340, 2020.

[10] W. L. Tian, S. Q. Yang, Y. H. Huang, and B. Hu, "Mechanical behavior of granite with different grain sizes after hightemperature treatment by particle flow simulation," Rock Mechanics and Rock Engineering, vol. 53, no. 3, pp. 1-17, 2019.

[11] C. Fan, S. Li, D. Elsworth, J. Han, and Z. Yang, "Experimental investigation on dynamic strength and energy dissipation characteristics of gas outburst-prone coal," Energy Science \& Engineering, vol. 8, no. 4, pp. 1015-1028, 2020.

[12] C. J. Fan, M. K. Luo, S. Li, H. H. Zhang, Z. H. Yang, and Z. Liu, "A thermo-hydro-mechanical-chemical coupling model and its application in acid fracturing enhanced coalbed methane recovery simulation," Energies, vol. 12, 2019.

[13] G. Feng, Y. Kang, T. Meng, Y.-q. Hu, and X.-h. Li, "The influence of temperature on mode I fracture toughness and fracture characteristics of sandstone," Rock Mechanics and Rock Engineering, vol. 50, no. 8, pp. 2007-2019, 2017.

[14] B. Chen, S. C. Zhang, Y. Y. Li, Z. K. Li, and H. J. Zhou, "Physical simulation study of crack propagation and 
instability information discrimination of rock-like materials with faults," Arabian Journal of Geosciences, vol. 13, p. 966, 2020.

[15] C. X. Wang, B. T. Shen, J. T. Chen et al., "Compression characteristics of filling gangue and simulation of mining with gangue backfilling: an experimental investigation," Geomechanics and Engineering, vol. 20, no. 6, pp. 485-495, 2020.

[16] C. Zhu, Z. G. Tao, S. Yang, and S. Zhao, "V shaped gully method for controlling rockfall of high-steep slope in China," Bulletin of Engineering Geology and the Environment, vol. 78, no. 4, pp. 2731-2747, 2019.

[17] J. Wang, Y. Zhang, Z. Qin, S. Song, and P. Lin, “Analysis method of water inrush for tunnels with damaged waterresisting rock mass based on finite element method-smooth particle hydrodynamics coupling," Computers and Geotechnics, vol. 126, Article ID 103725, 2020.

[18] X. Wang, C. Liu, S. Chen, L. Chen, K. Li, and N. Liu, "Impact of coal sector's de-capacity policy on coal price," Applied Energy, vol. 265, Article ID 114802, 2020.

[19] D. Liu, Z. Gu, R. Liang et al., "Impacts of pore-throat system on fractal characterization of tight sandstones," Geofluids, vol. 2020, Article ID 4941501, 17 pages, 2020.

[20] J. T. Chen, J. H. Zhao, S. C. Zhang, Y. Zhang, F. Yang, and M. Li, "An experimental and analytical research on the evolution of mining cracks in deep floor rock mass," Pure and Applied Geophysics, 2020.

[21] Z. T. Zhang, H. P. Xie, R. Zhang, M. Z. Gao, and E. S. Zha, "Size and spatial fractal distributions of coal fracture networks under different mining-induced stress conditions," International Journal of Rock Mechanics and Mining Sciences, vol. 132, Article ID 104364, 2020.

[22] Z. Jia, H. Xie, R. Zhang et al., "Acoustic emission characteristics and damage evolution of coal at different depths under triaxial compression," Rock Mechanics and Rock Engineering, vol. 53, no. 5, pp. 2063-2076, 2020.

[23] Z. Zhang, H. Xie, R. Zhang et al., "Deformation damage and energy evolution characteristics of coal at different depths," Rock Mechanics and Rock Engineering, vol. 52, no. 5, pp. 1491-1503, 2019.

[24] H. Zhao, F. Ma, J. Xu, and J. Guo, "In situ stress field inversion and its application in mining-induced rock mass movement," International Journal of Rock Mechanics and Mining Sciences, vol. 53, pp. 120-128, 2012.

[25] M. Gong, S. Qi, and J. Liu, "Engineering geological problems related to high geo-stresses at the Jinping I hydropower station, Southwest China," Bulletin of Engineering Geology and the Environment, vol. 69, no. 3, pp. 373-380, 2010.

[26] A. J. White, M. O. Traugott, and R. E. Swarbrick, "The use of leak-off tests as means of predicting minimum in-situ stress," Petroleum Geoscience, vol. 8, no. 2, pp. 189-193, 2002.

[27] B. Liu, Y. G. Zhu, Q. S. Liu, and X. W. Liu, "A novel in situ stress monitoring technique for fracture rock mass and its application in deep coal mines," Applied Sciences, vol. 9, 3742 pages, 2019.

[28] S. Zhang and S. Yin, "Determination of in situ stresses and elastic parameters from hydraulic fracturing tests by geomechanics modeling and soft computing," Journal of Petroleum Science and Engineering, vol. 124, pp. 484-492, 2014.

[29] J. Feng, L. Shang, X. Li, and P. Luo, "3D numerical simulation of heterogeneous in situ stress field in low-permeability reservoirs," Petroleum Science, vol. 16, no. 5, pp. 939-955, 2019.

[30] Y. Wang, J. Zhou, Y. D. Geng, B. Zhao, and C. T. Li, “Effect of fault on in-situ stress perturbation in deep carbonate reservoir," Chemistry and Technology of Fuels and Oils, vol. 55, no. 4, 2019.

[31] Z. F. Yuan, P. H. Xu, and Z. R. Ye, "Inversion of initial geostress in high and steep slope," Applied Mechanics and Materials, vol. 170-173, pp. 1325-1329, 2012.

[32] R. J. Ledingham and C. M. Merrifield, "In-situ stress measurements in the Carnmenellis granite-II. Hydrofracture tests at rosemanowes quarry to depths of $2000 \mathrm{~m}$," International Journal of Rock Mechanics \& Mining Sciences \& Geomechanics Abstracts, vol. 20, no. 2, pp. 63-72, 2000.

[33] H. Kang, X. Zhang, L. Si, Y. Wu, and F. Gao, "In-situ stress measurements and stress distribution characteristics in underground coal mines in China," Engineering Geology, vol. 116, no. 3-4, pp. 333-345, 2010.

[34] R. A. Irvin, P. Garritty, and I. W. Farmer, "The effect of boundary yield on the results of in situ stress measurements using overcoring techniques," International Journal of Rock Mechanics and Mining Sciences \& Geomechanics Abstracts, vol. 24, no. 1, pp. 89-93, 1987.

[35] N. R. Warpinski and L. W. Teufel, "In situ stress measurements at rainier mesa, Nevada test site-influence of topography and lithology on the stress state in tuff," International Journal of Rock Mechanics \& Mining Sciences \& Geomechanics Abstracts, vol. 28, no. 2-3, pp. 143-161, 1991.

[36] B. L. Wang and Q. C. Ma, "Boundary element analysis methods for ground stress field of rock masses," Computers \& Geotechnics, vol. 2, no. 5, pp. 261-274, 1986.

[37] L.-h. Zhang, "Pre-processing and post-processing method for geostress simulation using seismic interpretation results," Mining Science and Technology (China), vol. 19, no. 3, pp. 369-372, 2009.

[38] V. Saati and A. Mortazavi, "Numerical modelling of in situ stress calculation using borehole slotter test," Tunnelling and Underground Space Technology, vol. 26, no. 1, pp. 172-178, 2011.

[39] S. Sakurai and K. Takeuchi, "Back analysis of measured displacements of tunnels," Rock Mechanics and Rock Engineering, vol. 16, no. 3, pp. 173-180, 1983.

[40] J. L. Yang, "The FEM of 3-dimensional back-analysis of displacements," Rock \& Soil Mechanics, vol. 17, no. 3, pp. 1-7, 1996.

[41] Education Committee of Chinese Society of Rock Mechanics and Engineering, New Developments in Rock Mechanics, Northeast Institute of Technology Press, Shenyang, China, 1989.

[42] G. Y. Kong, M. F. Cai, and J. M. Zhu, “The application of stress function method in back-analysis of rock stress in a gold mine," Journal of Shenyang Institute of Gold Technology, vol. 15, no. 3, pp. 215-220, 1996.

[43] Y. T. Zhang, "Trend analysis of residual stress distribution in rock mass," Journal of Hydraulic Engineering, vol. 4, pp. 3340, 1984.

[44] K. Yang, L. X. Zhang, and Z. K. Li, "New method for calculating geostresses in FEM analysis of underground houses," Chinese Journal of Rock Mechanics \& Engineering, vol. 21, no. 11, pp. 1639-1644, 2002.

[45] J. H. Yu, W. L. Jin, and D. Q. Zou, "Displacement function method for analyzing initial earth stress," Rock \& Soil Mechanics, vol. 3, pp. 417-419, 2003.

[46] W. Meng and C. He, "Back analysis of the initial geo-stress field of rock masses in high geo-temperature and high geostress," Energies, vol. 13, no. 2, pp. 363-373, 2020.

[47] S. D. Mckinnon, "Analysis of stress measurements using a numerical model methodology," International Journal of Rock 
Mechanics and Mining Sciences, vol. 38, no. 5, pp. 699-709, 2001.

[48] C. Zhang, X.-T. Feng, and H. Zhou, "Estimation of in situ stress along deep tunnels buried in complex geological conditions," International Journal of Rock Mechanics and Mining Sciences, vol. 52, pp. 139-162, 2012.

[49] C. H. Fu, W. M. Wang, and S. H. Chen, "Back analysis study on initial geostress field of dam site for Xiluodu hydropower project," Chinese Journal of Rock Mechanics \& Engineering, vol. 25, no. 11, pp. 2305-2312, 2006.

[50] H. Q. Xie, J. D. He, and M. L. Xiao, "Regression analysis of 3D initial geostress in region of underground powerhouse for large hydropower station," Rock \& Soil Mechanics, vol. 30, no. 8, pp. 2471-2476, 2009.

[51] Y. S. Li, M. J. Yin, J. P. Chen, and J. Xu, "Analysis of 3D in-situ stress field and query system's development based on visual BP neural network," Procedia Earth \& Planetary Science, vol. 5, pp. 64-69, 2012.

[52] Z. F. Song, Y. J. Sun, and L. Xuan, "Research on in situ stress measurement and inversion, and its influence on roadway layout in coal mine with thick coal seam and large mining height," Geotechnical \& Geological Engineering, vol. 36, no. 3, pp. 1907-1917, 2018.

[53] Y. Da, S. H. Chen, and X. R. Ge, "A methodology combining genetic algorithm and finite element method for back analysis of initial stress field of rock masses," Rock \& Soil Mechanics, vol. 25, no. 7, pp. 1077-1080, 2004.

[54] D. J. Yu, Z. J. Yang, Y. H. Guo, Y. G. Yang, and B. Wang, "Inversion method of initial geostress in coal mine field based on FLAC3D transverse isotropic model," Journal of China Coal Society, 2020.

[55] L. D. Yang, Inversion Theory and Engineering Practice of Geotechnical Engineering Problems, Science Press, Beijing, China, 1996.

[56] L. Li, J. D. He, Z. W. Lin, and J. Yang, "Study on initial geostress of underground powerhouse of Nuozhadu power station," Hongshui River, vol. 22, no. 4, pp. 28-32, 2003.

[57] B. Hu, X. T. Feng, X. H. Huang, S. G. Su, and H. Zhou, "Regression analysis of initial geogress field for left bank high slope region at Longtan hydropower station," Chinese Journal of Rock Mechanics \& Engineering, vol. 24, no. 22, pp. 40554064, 2005. 